Original Research Article

\title{
A comparative study of epidural tramadol with epidural pentazocine for postoperativeanalgesia in patients undergoing lower abdominal surgeries
}

\author{
Yadhuraj M. K.*, Somasekharam P., Vinay D. M., Akhil Rao U. K.
}

Department of Anaesthesia, MVJ Medical College and RH Hoskote, Bangalore, Karnataka, India

Received: 09 September 2017 Accepted: 16 September 2017

*Correspondence to: Dr. Yadhuraj M. K., Email: dryadurajgowda@ gmail.com

Copyright: (C) the author(s), publisher and licensee Medip Academy. This is an openaccess article distributed under the terms of the Creative Commons Attribution NonCommercial License, which permits unrestricted noncommercial use, distribution, and reproduction in any medium, provided the original work is properly cited.

\begin{abstract}
Background: To evaluate and compare the efficacy of epidurally administered Tramadol. Hydrochloride and Pentazocine Lactate in providing post operative pain relief for lower abdominal and lower limb surgeries. To compare the side effects between epidural tramadol and pentazocine. Design of the study was a prospective randomized study.

Methods: The study population consisted of 100 patients aged between 18-65 years posted for various elective lower abdominal and lower limb surgeries requiring neuraxial anaesthesia at M.V.J. Medical College and Research Hospital, Hoskote, Bangalore. The study population was randomly divided into 2 groups with 50 patients in each sub group. Group T: Administered 50mg Tramadol, diluted to $10 \mathrm{ml}$ with Normal saline, epidurally $(\mathrm{n}=50)$ Group P: Administered $0.3 \mathrm{mg} / \mathrm{kg}$ Pentazocine, diluted to $10 \mathrm{ml}$ with Normal saline, epidurally $(\mathrm{n}=50)$. Patient was monitored on various parameters including duration of action, hemodynamic variables, and side effects.

Results: In group administered 50mg Tramadol epidurally, the mean time to onset of analgesia was $4.36 \pm 2.23$ mins and the mean time to onset of analgesia in the group administered pentazocine was $4.84 \pm 2.24$ mins, with a $p$ value of 0.286 , which is not considered significant. In tramadol group, the analgesic period averaged 7 hours 20 minutes, while the duration of analgesia in group P averaged 6 hours 43 minutes, with a p value of 0.475 , which is not considered significant. It was also observed that $0.3 \mathrm{mg} / \mathrm{kg}$ of pentazocine produced marginally higher incidence of bradycardia, dizziness, drowsiness.

Conclusions: With these results, we conclude that epidural tramadol 50mg gives longer lasting and more profound analgesia with lesser side effects when compared to $0.3 \mathrm{mg} / \mathrm{kg}$ of pentazocine.
\end{abstract}

Keywords: Epidural anaesthesia, Post operative analgesia, Pentazocine, Visual analog score, Tramadol

\section{INTRODUCTION}

Man has always tried to tame and subdue the crippling force that pain had always been, and in the process devised various methods to overcome it, ranging from black magic to application of ice and hypnosis to opium. In most instances, acute painful disorders are correctly diagnosed and effectively treated, but in a significant number of cases, patients with severe or very severe post operative and post traumatic pain and severe visceral pain are not effectively relieved. Modern day anaesthesia is not just concerned with relieving pain during surgeries but also during post operative period. Post operative analgesia is gaining more weightage as it not only improves quality of life of the patient, but also results in faster recovery and reduces medical costs.

Various modalities for post operative pain management are available today. Analgesia through the epidural route is one of the most preferred techniques for it. 
Various narcotics like morphine, pethidine, hydromorphone and fentanyl has been used for relief of post operative pain. ${ }^{1}$

However, epidural narcotic administration, while effective in relieving postoperative pain, may also be associated with significant side effects such as hypotension, respiratory depression, urinary retention and vomiting, and the search for a better agent continues. It is in this setting that the epidural uses of narcotic mixed agonist- antagonist agents like pentazocine and tramadol, has gained traction. These drugs by themselves administered intravenously or intramuscularly, may not be adequate in alleviating pain completely resulting from a major surgery like a caesarean section. $^{2}$

These drugs are easily available as well as inexpensive, but their epidural use has sparsely been reported, and hence this study of epidural pentazocine in comparison with epidural tramadol is undertaken to evaluate their feasibility as effective analgesics for post operative period.

\section{METHODS}

The present clinical study was conducted to evaluate the efficacy and safety of epidural tramadol $(50 \mathrm{mg})$ in comparison with epidural pentazocine $(0.3 \mathrm{mg} / \mathrm{kg})$ for post operative pain relief. The study was undertaken at M.V.J Medical College and Research Hospital, Hoskote, Bangalore during the period of 2012-2014.

Hundred patients undergoing various abdominal, perineal, vascular and lower limb surgeries were selected randomly. All the patients belong to ASA I or II and were aged between 18 to 65 yrs. Patients were randomly divided into two groups of 50 each. Group T received tramadol $50 \mathrm{mg}$ epidurally and Group P pentazocine $0.3 \mathrm{mg} / \mathrm{kg}$ epidurally during their post operative period.

Patients were visited on the previous day of the surgery and a detailed medical history was taken and systemic examinations were carried out. Basic laboratory investigations like $\mathrm{Hb} \%$, FBS, blood urea and serum creatinine and urine analysis were carried out routinely on all patients. ECG was done in patients more than 40 yrs of age and chest $\mathrm{X}$ ray when indicated. The entire procedure was explained to the patient and was asked to notify after surgery when the patient experiences pain. A written consent was obtained from the patient.

Tab. Alprazolam $0.5 \mathrm{mg}$ orally was given on the morning of the day of surgery. Patients were kept nil orally for 8 hours before surgery.

\section{Observations}

- Onset of analgesia

- Duration of analgesia

- Cardio respiratory effects

- $\quad$ Side effects (if any)
- All the observations and particulars of each patient were recorded.

\section{Technique}

Drugs and equipments necessary for resuscitation and general anaesthesia administration were kept ready. An autoclaved epidural tray was used.

The patient was made to lie supine on the operation table. Baseline blood pressure, heart rate and respiratory rate were noted. Then I.V line was secured with an $18 \mathrm{G}$ cannula and infusion was started. Then the patient was placed in right lateral position. With all aseptic precautions, a skin wheal was raised at L2-L3 interspace with $2 \mathrm{ml}$ of $2 \%$ lignocaine. The epidural space was identified using a $18 \mathrm{G}$ Touhy needle with loss of resistance to air technique. The $18 \mathrm{G}$ epidural catheter was passed through the epidural needle till about $5-6 \mathrm{~cm}$ of the catheter was in the space. Then the needle was withdrawn and the catheter was fixed to the back. $3 \mathrm{ml}$ of $2 \%$ lignocaine with adrenaline 1:200000 was injected through the catheter as a test dose and observed for any intravascular or intrathecal injection.

After confirming correct placement of the catheter, spinal anaesthesia was administered with plain $0.5 \%$ bupivacaine. Dose of drug was according to the patient, type of surgery and duration of surgery.

No narcotics were administered throughout the intra operative period. The patients were sedated intraoperatively with Inj. Midazolam 1-1.5mg.

Those cases where spinal blockade was inadequate with the need to administer general anaesthesia were excluded from the study. Rescue analgesia with Inj Pethidine $1 \mathrm{mg} / \mathrm{kg}$ was planned for those patients whose epidural analgesia was not satisfactory.

\section{RESULTS}

Table 1: Age distribution of the patients.

\begin{tabular}{|lllll|}
\hline Age in & \multicolumn{2}{l}{ Group T } & \multicolumn{2}{l|}{ Group P } \\
\hline years & No & $\mathbf{\%}$ & No & \% \\
\hline$\leq 20$ & 1 & 2.0 & 1 & 2.0 \\
\hline $21-30$ & 7 & 14.0 & 9 & 18.0 \\
\hline $31-40$ & 18 & 36.0 & 25 & 50.0 \\
\hline $41-50$ & 7 & 14.0 & 7 & 14.0 \\
\hline $51-60$ & 11 & 22.0 & 6 & 12.0 \\
\hline$>60$ & 6 & 12.0 & 2 & 4.0 \\
\hline Total & 50 & 100.0 & 50 & 100.0 \\
\hline Mean \pm SD & $44.14 \pm 13.79$ & $39.12 \pm 10.88$ \\
\hline
\end{tabular}

A large number of cases were in the age group of 31-40 years. The minimum age of patient was 18 and the maximum was 65 , with a mean age of 44 years in tramadol group and 39 years in pentazocine group. 
Table 2: Surgery classification of the patients.

\begin{tabular}{|lllll|}
\hline \multirow{2}{*}{ Depart } & \multicolumn{2}{c}{ Group T } & \multicolumn{2}{c|}{ Group P } \\
& No & \% & No & \% \\
\hline OBG & 23 & 46.0 & 23 & 46.0 \\
\hline Surgery & 13 & 26.0 & 13 & 26.0 \\
\hline Ortho & 14 & 28.0 & 14 & 28.0 \\
\hline Total & 50 & 100.0 & 50 & 100.0 \\
\hline
\end{tabular}

Table 3: Onset of analgesia.

\begin{tabular}{|lllll|l|}
\hline $\begin{array}{l}\text { Onset of } \\
\text { action(mins) }\end{array}$ & Group T & \multicolumn{2}{l|}{ Group P } & P \\
\hline $1-2$ & No & \% & No & $\%$ & Value \\
\hline $3-5$ & 6 & 12.0 & 6 & 12.0 & 1.000 \\
\hline $6-10$ & 35 & 70.0 & 28 & 56.0 & 0.378 \\
\hline$>10$ & 9 & 18.0 & 15 & 30.0 & 0.221 \\
\hline Total & 0 & 0.0 & 1 & 2.0 & 0.317 \\
\hline
\end{tabular}

The mean time to onset of analgesia in Group $\mathrm{T}$ was 4.36 \pm 2.23 mins and the value in Group $\mathrm{P}$ was $4.84 \pm 2.24$ mins, which did not have a significant difference between them $(\mathrm{p}=0.874)$.

Table 4: Duration of analgesia.

\begin{tabular}{|llllll|}
\hline $\begin{array}{l}\text { Duration } \\
\text { (hrs) }\end{array}$ & \multicolumn{2}{l}{ Group T } & \multicolumn{2}{l|}{ Group p } & P value \\
\hline $1-5$ & No & \% & No & \% & \\
\hline $6-10$ & 24 & 48.0 & 26 & 52.0 & 0.777 \\
\hline $11-15$ & 16 & 32.0 & 17 & 34.0 & 0.861 \\
\hline $16-20$ & 7 & 14.0 & 7 & 14.0 & 1.000 \\
\hline Total & 50 & 6.0 & 0 & 0.0 & 0.083 \\
\hline
\end{tabular}

The duration of analgesia in group $\mathrm{T}$ ranged from 1 hour to 16.30 hours, with an average of 7 hours 20 minutes. The duration of analgesia in group $P$ ranged from 2 hours to 15.45 hours, with an average of 6 hours and 43 minutes. The difference in duration of analgesia between the two groups is not significant, with a $\mathrm{p}$ value of 0.325 . In both the groups, there is no significant correlation between age, sex and the duration of analgesia. The wide range of pain relief seen with the same quantity of tramadol or pentazocine may be due to individual variation in the pain threshold.

A total of 9 patients in group $\mathrm{T}$ and 12 patients in group $\mathrm{P}$ complained of any side effects. $8 \%$ patients in group $\mathrm{T}$ had nausea while $2 \%$ vomited in the same group, in comparison to $6 \%$ of the patients who complained of nausea in group $\mathrm{P}$ and $0 \%$ of patients vomiting in the same group. An equal number of 4 patients $(8 \%)$ patients in either group complained of drowsiness. $6 \%$ of patients had bradycardia, $2 \%$ patients had dizziness and $2 \%$ patients had irritability in group $\mathrm{P}$ while these side effects did not occur in group $\mathrm{T}$. There were no other side effects like respiratory depression, pruritis or hypersensitivity reaction.
Table 5: Side effects.

\begin{tabular}{|lllll|}
\hline \multirow{2}{*}{ Side effects } & \multicolumn{2}{l}{ Group T $(\mathbf{n = 5 0})$} & \multicolumn{2}{l|}{ Group P $(\mathbf{n = 5 0})$} \\
\cline { 2 - 5 } & No & $\mathbf{\%}$ & No & $\mathbf{\%}$ \\
\hline No & 41 & 82.0 & 38 & 76.0 \\
\hline Yes & 9 & 18.0 & 12 & 24.0 \\
\hline Bradycardia & 0 & 0.0 & 3 & 6.0 \\
\hline Dizziness & 0 & 0.0 & 1 & 2.0 \\
\hline Drowsiness & 4 & 8.0 & 4 & 8.0 \\
\hline Irritability & 0 & 0.0 & 1 & 2.0 \\
\hline Nausea & 4 & 8.0 & 3 & 6.0 \\
\hline Vomited & 1 & 2.0 & 0 & 0.0 \\
\hline
\end{tabular}

Table 6: Pain scoring.

\begin{tabular}{|llll|}
\hline Post op period & Group p & Group t & P value \\
\hline $1 \mathrm{hr}$ & 0.77 & 0.69 & 0.947 \\
\hline $2 \mathrm{hr}$ & 1.18 & 0.97 & 0.514 \\
\hline $4 \mathrm{hr}$ & 2.42 & 1.86 & 0.337 \\
\hline $6 \mathrm{hr}$ & 3.61 & 2.64 & 0.234 \\
\hline $8 \mathrm{hr}$ & 3.82 & 2.44 & 0.201 \\
\hline $12 \mathrm{hr}$ & 4.20 & 2.73 & 0.183 \\
\hline $16 \mathrm{hr}$ & 3.78 & 2.16 & 0.187 \\
\hline $20 \mathrm{hr}$ & 2.67 & 1.87 & 0.301 \\
\hline $24 \mathrm{hr}$ & 2.24 & 1.84 & 0.365 \\
\hline
\end{tabular}

Background pain during the post operative 24 hour study period was studied, at hours 1, 2, 4, 6, 8, 12, 16, 20 and 24 hours after the administration of the study drugs. The pain scoring was done with Visual Analog Score. During the course of the study period, Group T patients consistently had lower pain scores than patients in Group P, but the difference was not significant, with a $p$ value of 0.183 at 12th hour, when the difference in pain scores between the two groups were the maximum. None of the patients required rescue analgesia with $\mathrm{Inj}$. Pethidine $1 \mathrm{mg} / \mathrm{kg}$.

\section{DISCUSSION}

Management of post operative pain still remains an enigma. ${ }^{3}$ Paradoxically, after all the efforts taken to make the intraoperative period pain and stress free, the patient is often left to fend for himself in the post operative period. Perfect pain relief is not attainable in practice and sometimes not even desirable, since pain is a protective mechanism and pain on excessive movement may persuade the patient to take proper rest after surgery or trauma.

To be pain free at rest is a reasonable goal. Pain relief is necessary for both humanitarian and therapeutic reasons. Uncontrolled pain in the post operative period can have detrimental physiological effects.

- Pain can greatly impede the return of normal pulmonary function - splinting, inability to cough, bronchospasm - all lead to atelectasis and hypoxemia especially in upper abdominal and thoracic surgeries. 
- Pain promotes immobility and hence the development of deep vein thrombosis.

Alteration in the stress response to surgery, increased catecholamine release, increased oxygen demand and increased cardiac work.

- Increased catabolic response to surgical trauma and impaired immune mechanisms and delayed wound healing.

Hence its relief undoubtedly decreases morbidity and mortality. Anaesthesiologists are the logical choice to be involved in the management of post operative analgesia.

- As they obtain a feel for dose requirement during management of anaesthesia.

- $\quad$ Familiarity with analgesics, team work and dexterity with nerve blocks.

Prerequisite of an analgesic technique is to relieve pain, to free the patient from reflex motor inhibition of respiratory movement.

The safety of any analgesic system lies in the width of margin between the positive effects of pain relief and restoration of function on one hand and the negative effects of respiratory depression on the other. The epidural narcotics have a wider margin of safety as against systemic narcotics.

In recent times, the role of epidural and subarachnoid opioids for the relief of post operative pain promises a new platform in this field. This is because of the direct action of the narcotics on specific opioid receptors that are richly distributed in the posterior horn of the spinal cord.

Although epidural administration is perceived by majority of anaesthetists as the ideal analgesic technique for surgeries such as upper abdominal surgery, only a small minority of patients undergoing major surgeries receive post operative pain management via epidural route. The main factor which has limited the use of epidural analgesia has been the difficulty in making a reasonable risk/benefit analysis about the technique, which has resulted in clinicians constantly asking whether epidurals are effective for postoperative pain relief and whether the technique is safe.

The ideal epidural analgesic technique for major surgery would provide effective pain relief with minimal side effects and high levels of patient satisfaction. It would also obtund central sensitization and pain-induced organ dysfunction, leading to improved outcome.

Woodforde and Merskey first reported use of the VAS pain scale with "no pain at all" at one end and "my pain is as bad as it could possibly be" at the other end of the scale in patients with a variety of conditions. The pain VAS originated from continuous visual analog scales developed in the field of psychology to measure well-being. Morphine and pethidine remain the standard drugs used for post operative pain. ${ }^{4}$ But they are associated with respiratory depression, vomiting and addiction potential. For many years, these potent narcotic agents were in use for post operative pain relief and it seemed as if analgesia, emesis, respiratory depression and addiction potential were inseparable. Exceptions to this statement are tramadol and pentazocine.

Tramadol hydrochloride is an agonist-antagonist narcotic drug which was introduced in Germany in 1971 and is currently available throughout the world. ${ }^{5}$

It is a modestly potent opioid analgesic which interacts with $\mu, \delta$ and $\lambda$ opioid receptors where it exerts purely its agonist effects. This drug has been used for moderate to severe pain management. ${ }^{6}$ Tramadol is a centrally acting analgesic whose mechanism is predominantly based on enhanced serotonergic neurotransmission and therefore its analgesic efficacy can be blocked by $5 \mathrm{HT} 3$ receptor antagonist ondansetron. It also inhibits norepinephrine transporter function. Its toxicity includes association with seizures; the drug is relatively contraindicated in patients with a history of epilepsy and for use with other drugs that lower seizure threshold. Other side effects including nausea and dizziness typically abate following several days of therapy. No clinically relevant effects on respiration or cardiovascular system have thus far been reported in literature. ${ }^{7}$ Of late, its use in chronic neuropathic pain has been of increasing interest.

Pentazocine is a synthetic agonist-antagonist type of opioid and is a benzomorphan derivative. It is an agonist at $\mathrm{k} 1$ opioid receptor, and used for relief of moderate pain. It also acts as a weak antagonist or partial agonist at $\mu$ receptors. ${ }^{9}$ In equianalgesic doses, pentazocine causes same degree of respiratory depression as morphine, however, as with other partial agonist In our study, patients between 18-65 years of age were chosen. They were randomly selected without any criteria for sex distribution.

There sponse curves for respiratory depression and analgesia are plateau shaped, which is reached ata dose of $60 \mathrm{mg}$ in an average adult.

Pentazocine is contraindicated in the treatment of patients with myocardial infarction due to cardiovascular stimulation caused by it. Psychmimetic side effects such as hallucinations, bizarredreams and sensations of depersonalization occur in $6-10 \%$ of patients. Nausea occurs in about $5 \%$ of patients though vomiting is less common. Risk of physical dependence is low.

Pentazocine crosses placenta and may cause foetal depression. ${ }^{10}$ Severe injection site necrosis and sepsis have occurred with multiple injections of pentazocine. Also, rarely it has been associated with agranulocytosis, erythema multiforme and toxic epidermal necrolysis.

In 1983, Praveen K. Kalia et al studied administration of $0.3 \mathrm{mg} / \mathrm{kg}$ Pentazocine epidurally, diluted to $10 \mathrm{ml}$ with 
normal saline, for post operative pain relief. In their study, the mean onset of action was $2.55 \pm 1.27$ mins. In our study, the mean onset of action of pentazocine was $4.84 \pm 2.24$ mins. $^{11}$

In 2013, Akrity Singh et al performed a comparative study of epidural Bupivacaine and bupivacaine with tramadol. In their study, a mean onset time of analgesia of $19.45 \pm 1.66$ mins was noted, while in our study, the mean onset time was $4.36 \pm 2.23$ mins. $^{12}$

In 1991, Rudra A, et al performed a randomised study of the efficacy, duration of action and side-effects of two analgesic regimens following lower abdominal surgery, with epidural pentazocine and epidural buprenorphine. ${ }^{13}$ In their study, the mean duration of analgesia by pentazocine was 8.39 hours while in our study, mean duration of analgesia in group P was 6 hours 43 mins, with a range of 2 hours to 15.45 hours. $^{14}$

\section{CONCLUSION}

The centrally acting opioid analgesic, Tramadol hydrochloride, appears to be a promising agent in relieving post operative pain with a good margin of safety when compared to Pentazocine lactate.

With these results, we conclude that epidural tramadol $50 \mathrm{mg}$ gives longer lasting and profound analgesia with minimal side effects when compared to $0.3 \mathrm{mg} / \mathrm{kg}$ of pentazocine. The main feature of this study is that the single injection administered in the post operative period by the anaesthesiologist will ensure satisfactory post operative analgesia of sufficient duration. This avoids the repeated injections required in the ward. The patient remains comfortable and pain free. Above all, this is a simple and cost effective method. In view of its safety profile, epidural tramadol can be routinely employed in our set up in the

management of acute post operative pain for various surgical procedures.

Funding: No funding sources Conflict of interest: None declared

Ethical approval: The study was approved by the Institutional Ethics Committee

\section{REFERENCES}

1. Kolawole IK, Fawole AA. Post operative pain management following Caesarean section. WAJM. 2003;22(4):305-9.

2. Bonica JJ. History of pain concepts and therapies. The Management of Pain; $2^{\text {nd }} E d .1990: 2-11$.
3. Stoelting RK. Opioid Agonists and Antagonists. Pharmacology and Physiology in Anaesthetic Practice, $3^{\text {rd }}$ Ed; 1999:77-112.

4. Howard B, Stein G, Huda A. Opioid analgesics. The Pharmacological Basis of Therapeutics, $10^{\text {th }} \mathrm{Ed}$; 2001:569-619.

5. Kalia PK, Madan R, Saksena R, Batra RK, Gode GR. Epidural pentazocine for postoperative pain relief. Anesthesia \& Analgesia. 1983 Oct 1;62(10):949-50.

6. Chawla R, Arora MK, Saksena R, Gode GR. Efficacy $\&$ dose-response of intrathecal pentazocine for postoperative pain relief. The Indian journal of medical research. 1989 Jun;90:220-3.

7. Rudra A, Roy S, Gupta K, Kundu JP. Postoperative analgesia with extradural buprenorphine and pentazocine. Journal of the Indian Medical Association. 1991 May;89(5):123-4.

8. Fu YP, Chan KH, Lee TK, Chang JC, Daiy YP, Lee TY. Epidural tramadol for postoperative pain relief. Ma zui xue za zhi= Anaesthesiologica Sinica. 1991 Sep;29(3):648-52.

9. Vickers MD, O'flaherty D, Szekely SM, Read M, Yoshizumi J. Tramadol: pain relief by an opioid without depression of respiration. Anaesthesia. 1992 Apr 1;47(4):291-6.

10. Houmes RJ, Voets MA, Verkaaik A, Erdmann W, Lachmann B. Efficacy and safety of tramadol versus morphine for moderate and severe postoperative pain with special regard to respiratory depression. Anesthesia \& Analgesia. 1992 Apr 1;74(4):510-4.

11. Striebel HW, Hackenberger J. A comparison of a tramadol/metamizole infusion with the combination tramadol infusion plus ibuprofen suppositories for postoperative pain management following hysterectomy. Der Anaesthesist. 1992 Jun;41(6):35460.

12. Dauber A, Ure BM, Neugebauer E, Schmitz S, Troidl $\mathrm{H}$. The incidence of postoperative pain on general surgical wards. Results of different evaluation procedures. Der Anaesthesist. 1993 Jul;42(7):448-54.

13. Lee CR, Mc Tavish D, Sorkin EM. Tramadol: a prelim inary review of its pharmacodynamic and phammacokinetic properties, and therapeutic potenrial in various acute and chronic pain states. Drugs. 1993;46:13.

14. Delilkan AE, Vijayan R. Epidural tramadol for postoperative pain relief. Anaesthesia. 1993 Apr $1 ; 48(4): 328-31$.

Cite this article as: Yadhuraj MK, Somasekharam P, Vinay DM, RaoAUK. A comparative study of epidural tramadol with epidural pentazocine for postoperativeanalgesia in patients undergoing lower abdominal surgeries. Int J Basic Clin Pharmacol 2017;6:2441-5. 